\title{
Sense of Place: Understanding Architectural and Landscape Design through a Layering of Visual Representations
}

\author{
Kate Baker \\ School of Architecture \\ University of Portsmouth, UK. \\ kate.baker@port.ac.uk
}

\begin{abstract}
The context-free "object building," the sculptural form, reigned in schools of architecture for decades. As we are finally moving on from 20th century modernism, there is an urgency to re-place buildings within their contexts. All too often, students with a background in the discipline of architecture, struggle to design buildings that truly inhabit their surroundings and engage in any meaningful way within their physical context. Software libraries of plant species and hard-landscape details are available. But the problem lies deeper than overlaying some tasteful silver birches onto an image of a building. This article will discuss some of the methodologies we use with post-graduate students to give landscape equal importance to the building itself. We also challenge the sole use of CAD as the primary means of representation and put forward an argument for making use of a range of visual techniques. The relationship between landscape and architecture is a dialogue between interior and exterior space. It demands a means of representation that allows a reading of the continuity of spatial experience that gives us a "sense of place."
\end{abstract}

Keywords

Architectural education, Cross-disciplinary approach: Landscape, Film, Representation.

\section{Introduction}

My colleague, Nick Timms and I run a Studio for students in their final year at the School of Architecture, University of Portsmouth, UK, entitled Architecture and Landscape. It is based on the premise that gaining an understanding of what we mean by a "sense of place" in the design process is critical. This means identifying ourselves in relation to a particular place through disseminating its "genius loci," the spirit of the place, and expressing our own perceptions and responses to it. The understanding of Garden and the Park as mediators between architecture and landscape has been central to our work, with Steenbergen and Reh's (2003) "Architecture and Landscape" as one of our key texts.

We ask our students to tease out the unique qualities of a landscape and insist that these are prerequisites to design proposals. We encourage students to explore the continuity of our experience of architecture and its context, and what we mean by the idea of "place-making." The studio group typically varies in size between 9-12 students and collaborative as well as individual work is encouraged. Over the last decade we have developed a range of investigative and representational techniques to promote the understanding of "place" as a necessary point of departure for the design process. The first semester consists of short projects that provide a working method for their final thesis in the second. 
We have found it useful to choose a site that relates to a particular theme. For example, we chose Painshill Park a (near Cobham in Surrey, UK) last year, and investigated aspects of "the ruin." Painshill Park was established in the $18^{\text {th }}$ century by Charles Hamilton and is known for its follies, one of which is a fake "gothick" ruin. By the time the students started their final thesis, located in a real ruined landscape, they were familiar with discussions covering the wide range of interpretations of "ruin" and its relevance in different contexts, from the comfortable additions to $18^{\text {th }}$ and $19^{\text {th }}$ century gardens to the wasted landscapes of abandoned settlements.

A number of exercises are carried out designed to be an iterative and accumulative process. They take place both on site and in the studio, collectively and individually. They vary from being purely analytical to being completely intuitive responses. The final stage of this first half of the year is a short design exercise. The year culminates in a Thesis Project - a comprehensive architecture/landscape proposal supported by an argument and proposition, developed through a group strategy. The intention is that students use the earlier learning exercises as a means of informing their thesis design.

The students work on two locations throughout the year.

a. The first: local (UK), accessible, with a strongly discernable identity or "sense of place." This is the vehicle for the initial representational exercises.

b. The second: abroad, European, a "ruined" landscape with wider issues that relate specifically to contemporary concerns.

The main emphasis is placed on "discovery" in the first location, with greater emphasis is on "application" in the second. This paper will focus on the initial exercises, the acquisition of skills and insights that can be applied in the second half of the year.

Sites for the initial exercise are chosen in locations where the landscape has previously been composed and transformed at a large, or even grand scale. We choose parks that have been designed through very clear principles that cover formal, metaphorical and practical considerations, developed over a long stretch of time; situations where a range of architectural devices have been used to hold the composition of the landscape together as a whole, and at the same time help choreograph our journeys through it.

Two of the locations we have visited for the initial exercise are the famous gardens of Stowe, Buckinghamshire, and Stourhead, Wiltshire. The houses and landscapes provided the opportunity to discuss complex ideas that arose in the $18^{\text {th }}$ Century and how these were played out in garden design. "Garden" had a significant role in aesthetic debate, demonstrating clearly articulated attitudes toward Nature (Symes, 2012). The students were faced with responding to these planned landscapes, questioning their purpose, seeing beyond nostalgia for the past (Buchanan, 2012). How have they has stood the test of time through alterations made by subsequent owners? How have the buildings and the planting developed and matured? Is the idea of narrative, that we see so clearly at Stourhead, (attributed to Henry Hoare and Henry Flitcroft), still a relevant way of constructing a landscape in the $21^{\text {st }}$ Century? Can we make use of picturesque notions of revelation, the unfolding of a narrative through scenographic discovery in terms of our $21^{\text {st }}$ century perceptions through filmic understanding of place? (Bruno, 2007) Even more importantly, it is a useful means to start to discuss our own values and attitudes to nature, climate and the diminishing resources of the $21^{\text {st }}$ Century.

\section{Learning experiences}

The overall aim for students in the first half of the year, after a careful study and immersion into the landscape, is to design a small intervention that respects it. It must make a positive contribution to the landscape by creating a place that reflects $21^{\text {st }}$ century design principles and contribute to a particular locale. As Tilley (1994) stated: "precisely because locales and their landscapes are drawn on in the day-to-day lives and encounters of individuals they possess powers. The spirit of a place may be held to reside in a landscape" (p. 26). 
The initial tasks overlap and partially run in parallel. They vary in detail from year to year depending on the site and nature of the project, but the underlying principles remain the same. Our objective is for the students to demonstrate an understanding of a landscape through direct experience as well as through research into its background. This is carried through a range of techniques that will be described below. For students to capture the "spirit of the place" and to unpack what we mean by "sense of place" we have adopted a method through discovery and application, as forerunners for their major design. This article will focus mainly on discovery, which can loosely be described as visiting and researching sites through a series of different "readings"; collecting and interpreting facts and data. Application is seen as the testing of that knowledge through design; the knowledge gained through discovery is applied to a design project that demands a "sense of place."

\section{Discovery}

\section{Background knowledge, data collection}

A range of graphic techniques is used to record and analyse factual information. Students are encouraged to present their work with as much visual communication as possible.

Conventional architectural drawings such as plans, sections, axonometric projections and figureground drawings are used and will often be the basis for diagrammatic analysis. The use of the diagram is taken seriously as an economic means of communicating ideas and a very effective means of conveying geographical/topographical/geological/botanical information (Figure 1). An illustrated time-line, for example, shows the historical and cultural background, including a description of human intervention on the land. Students are encouraged to use a variety and mixture of techniques, such as making use of hand-drawing over. Measured drawings are used to record the lie of the land. Accurate graphic representation of the landscape through architectural, and cartographical conventions is seen as essential information and a pre-requisite for designing in any detail. An important aspect of the early research is to gather information about the architectonic landscape devices that have been used. Through this students start to build up a vocabulary of design methods for handling the landscape that can be applied later on in the project (Figure 2).

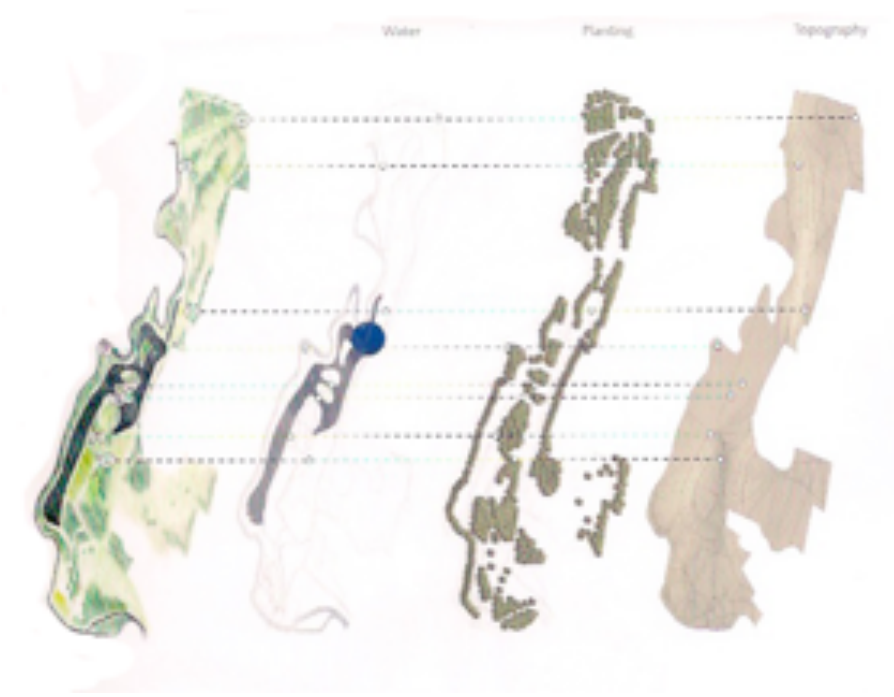

Figure 1. Topographical analysis Painshill Park - Student groupwork 


\section{Understanding through experience. Drawing as a means of expression. Understanding and interpreting "atmosphere"}

As Tilley (1994) contended, "the very physicality of the body imposes a schema on space through which it may be experienced and understood" (p. 16). Students are asked to be conscious of their presence. We ask them to keep large sketchbooks (Jones, 2011) from the first day they arrive on site, and throughout the project. We encourage them to use these books more as scrap books of ideas than traditional sketchbooks, that will record thoughts and ideas, expressing conceptual thinking in the form of rough and detailed sketches, text and annotation - using their own words or fragments of relevant literature and testing out spatial ideas through drawing. We are mindful of Pallasmaa's (2009) insistence of the importance of drawing and the imagination:

The pencil in the architect's hand is the bridge between the imagining mind and the image that appears on the sheet of paper; in the ecstasy of work, the draughtsman forgets both his hand and the pencil, and the image emerges as if it were an automatic projection of the imagining mind.

(Pallasmaa, 2009, p. 17)

Emphasis is given to sketching as an important part of the design process at all times, recording thought and acting as a visual "aide mémoire." Students are encouraged to use a pencil to record their first impressions of the landscape rather than take photographs. At a later stage, after further consideration of the location, they return and examine areas they have developed some affinity for in more detail to bring out the spatial quality and "feel" of the place they have chosen. They are encouraged to look at the detail, texture and light quality. This exercise is mainly carried out through conventional representational drawing techniques (Figure 2). It should be noted that we do not ban the use of photographic record, but encourage students to be interpretive and selective of what they record.

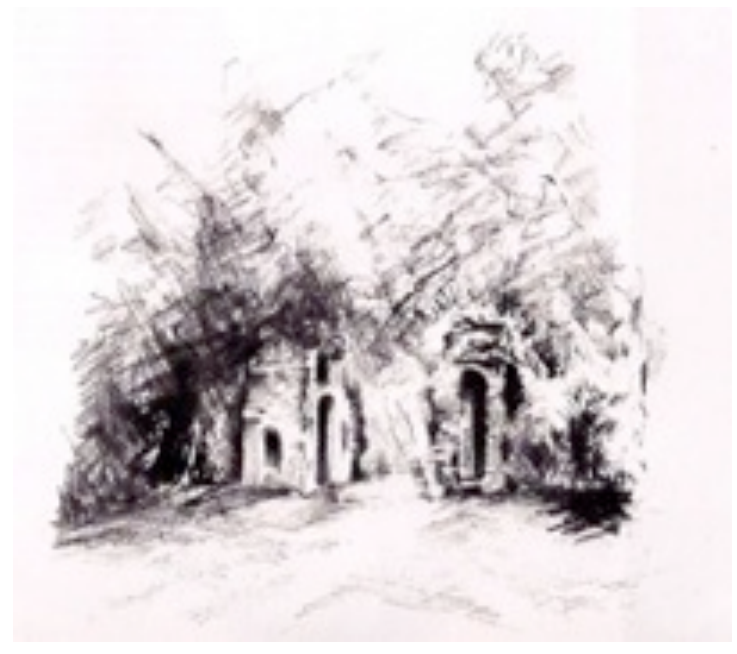

Figure 2. Painshill Park (Derek Williams)

We coordinate studio-based workshops, run by artist, Rose Nag. In 2011, Rose Nag explained to students that they are to:

... begin with loose studies in which marks and lines intertwine as if making continuous connections between the detail and the greater space. Think of these as a series of studies in which you "excavate" your recollections ... seeking a visual extraction which gradually begins to have specific spatial qualities and in which form space light and texture are revealed. 
The workshops bring out more subjective ways for the students to express their experiences of the place they have been studying. Rose Nag guides them through appropriate ways of being able to capture a "sense of place" by using a mixture of media techniques. The palette of materials is nonstandard for architects, such as charcoal, chalk or ink, which encourage looser and more gestural marks. It enables students to explore less representational and more subjective and emotional responses to the site, to be able to recall a particular atmosphere. Students are often tentative about expressing themselves this way, but after a day's drawing on large sheets of paper, that involves quite a lot of "letting-go" and a fair bit of mess, they produce work that enables them to make use of visual material that expresses ideas, atmosphere and emotional responses to their sites (Figure 3).
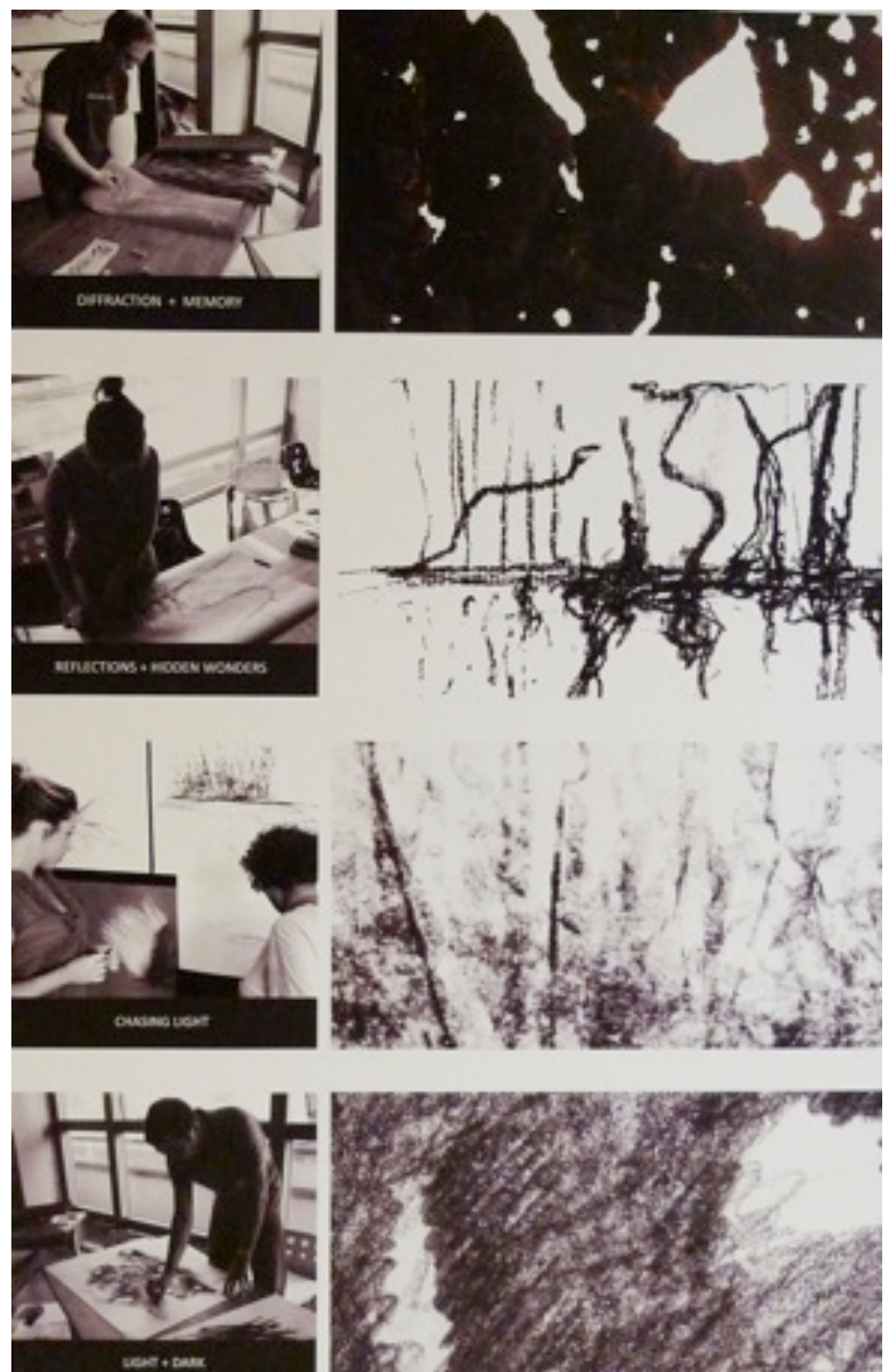

Figure 3. Workshop with Rose Nag 


\section{Film}

Much has been written about film and architecture. Amongst other aspects, the two art forms both rely on being understood visually and over time. As we move through a building or landscape it constantly reveals itself to us. Film gives us the opportunity not only to record, but also, through our own experience of it, to interpret it as a narrative in time. Perceptions of architecture and its context through time as the body moves through space have often been described as "cinematic" (Nesbitt, 1996). For this reason we have introduced the making of a short film into the programme. In pairs, students make a 5-minute video of their interpretation of a "sense of place." Sophisticated video equipment is now very accessible with quality good enough for students to produce short films at little cost. As Lamster (2000) argued, film has been the defining art form of the twentieth century, and consequently our perceptions of the places we inhabit are influenced by portrayal of locations seen in cinematic images, observed through the lens of the artistic director. Harper and Rayner (2010) further discussed the usefulness of film within the discipline of geography by talking about:

Film, composed of frames of reference as well as frames of composition, largely presents its art as a serial choice. Depiction of landscapes, as complex combinations of found or chosen features, emphasise the incredible variety of possible interrelations that make up the world; cinematic landscapes ... rely on the framework to both suggest a reading and limit the range of interpretations. (p. 18)

This equally applies to architectural design.

Giulia Bruno (2007) also pointed out that the Picturesque movement in landscape design, when Stowe and Stourhead came into being, can be seen as the forerunner to film. This is because the gardens of that period were designed specifically (often with an underlying narrative) for us to walk through and experience, discover views and observe the detail. Looking through a lens, shooting a film and editing it as part of the process of making a movie, however short, will alter what we see and how we see it. Students' perceptions change through making the video. Using film to map a location through the camera's eye, and observing a place in an experiential way can offer insights that drawings and photographs alone cannot do (Bruno, 2007).

A storyboard is first made from a limited number of freehand drawings/cartoons, using conventions of the filmmaking process. Each cartoon has to represent key stages, indicating the storyline and sequence of events of the film. The mood of the movie is taken seriously. Students are encouraged to refer back to the earlier free-hand experimental drawings, and to add an appropriate sound track that responds to their experiences. The introduction of some form of narrative, events and ideas unfolding over time, becomes the precursor to the next stage of the design process. The film-making is not only a creative process, but also an important part of their critical analysis of the site through direct involvement; they have to investigate it with a purpose. The film acts as the launch pad for the students' own architectural and landscape designs. Figure 4 illustrates the final preparation work after the storyboard has been made. 


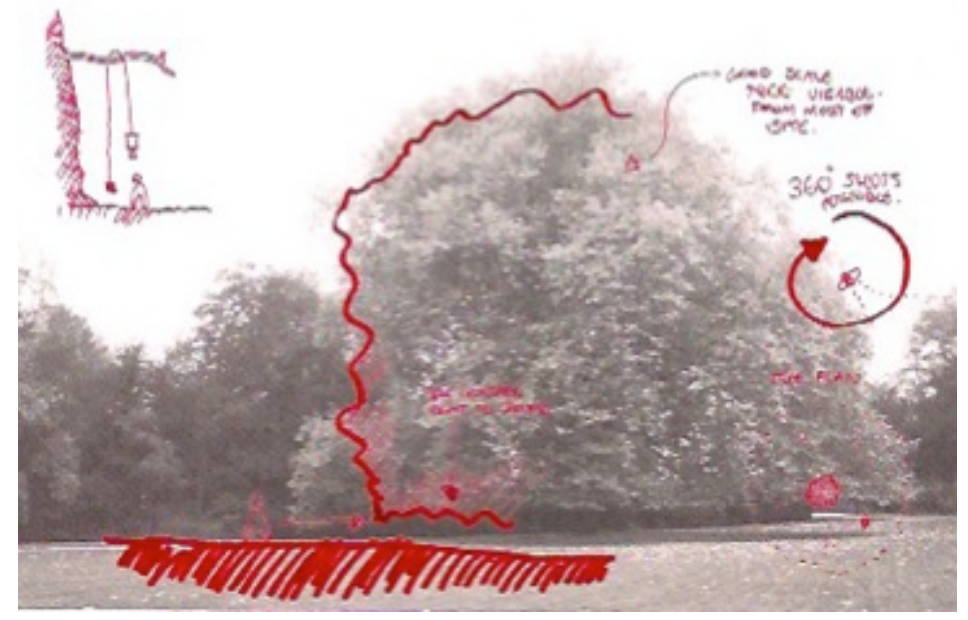

Figure 4. Filming Sequence, Mottisfont Abbey (Darren Leech \& Ricardo Marques)

In parallel with the visually based exercises, students work on a written critical analysis. This is a 5000 word, illustrated, critical essay, where they develop their individual interests and attitudes toward aspects of landscape and architecture. It allows students to investigate topics in detail and express their thoughts, ideas and processes they have undertaken thus far in the year. We encourage them to analyse case studies in depth, and using visual means to accompany the text. The writing is also a valuable tool for enabling them to articulate an argument that will underpin their final thesis design.

\section{Application}

Applying knowledge and insights and adding: speculation, imagination, analysis, deduction

Each student chooses a specific location and is asked to design an installation within it.

Before they start, and bearing in mind the film sequences the students have just completed, a group strategy has to be argued through that will connect all the individual projects and by so doing create new and alternative ways of experiencing the landscape park they have been working on. (see Figures 5, 6)

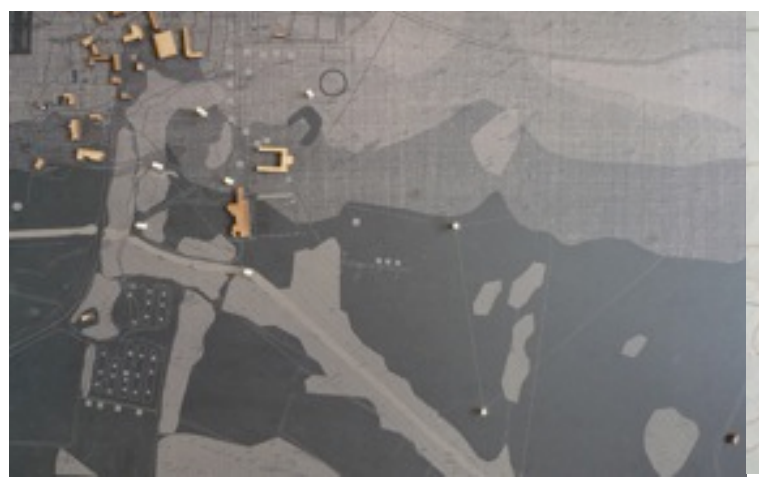

Figure 5. Site Analysis, Mottisfont Abbey. Mixed media, student group model.

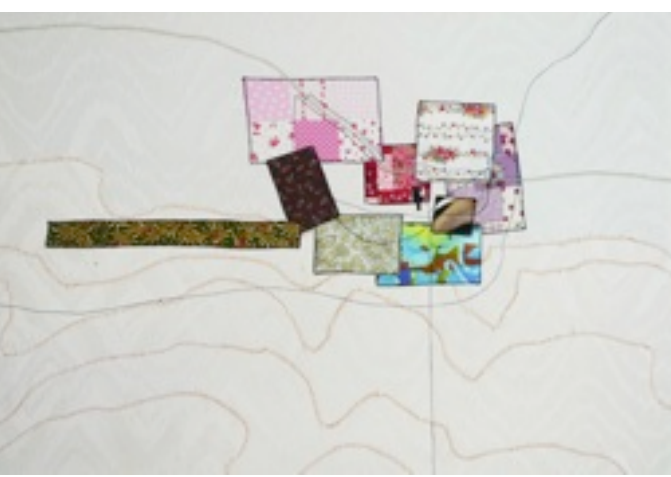

Figure 6. Site Strategy, Mottisfont Abbey. Sewn by Pavlo Lysytsya.

Importantly, the strategy becomes a means of combining the $21^{\text {st }}$ century ideas with those from previous generations see (Figure 7). 

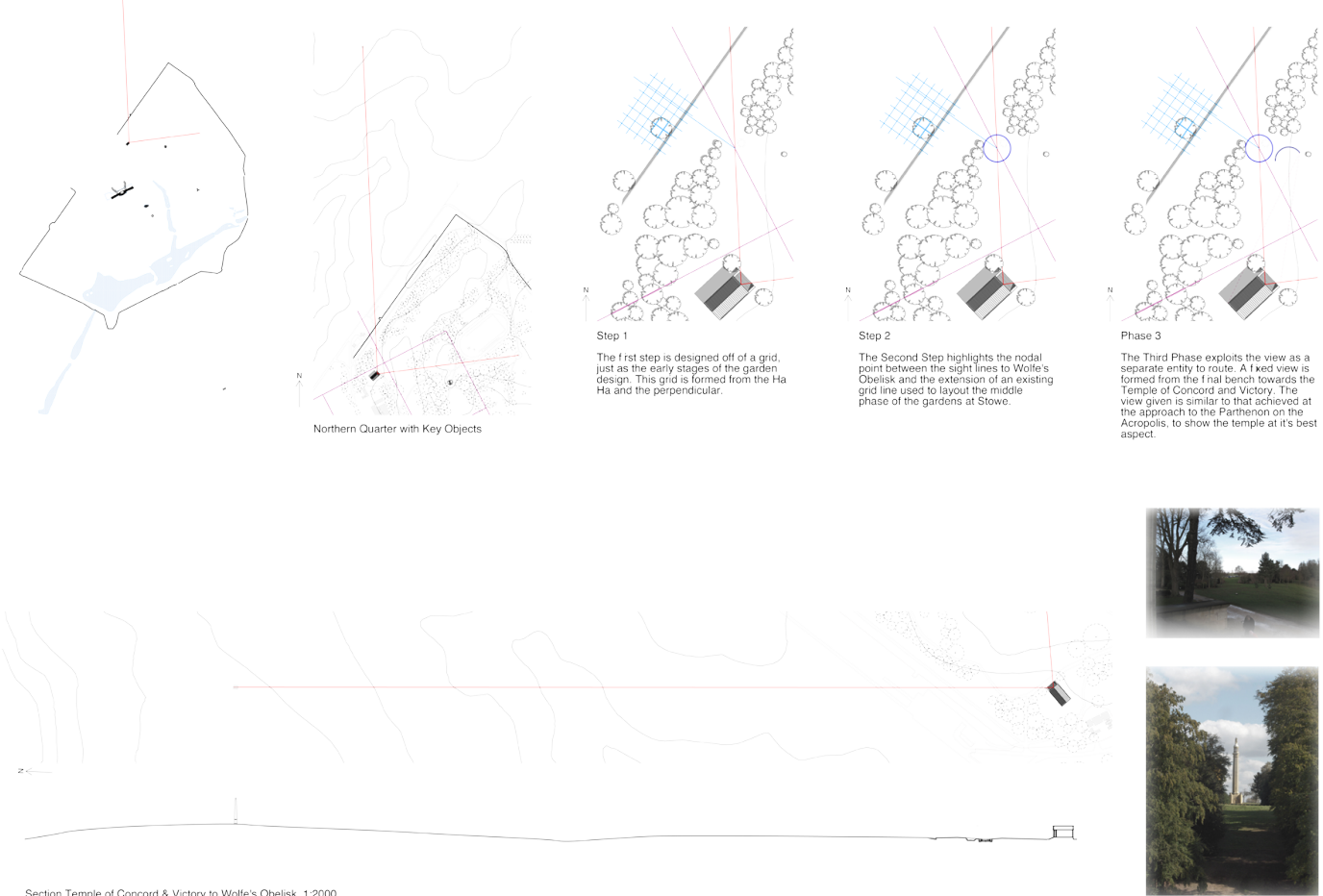

Figure 7. Rationale for new entrance to Stowe Garden (Mark West)

We provide a thematic program for the intervention, which usually takes the form of a "sitootery," or place for encounter for a small group of people. We also try to suggest ways of creating the atmosphere of the place. In 2012, for example, we asked students to create a shelter to house a poem. The poems were chosen from the $19^{\text {th }}$ and late $20^{\text {th }}$ century, that expressed each poet's feelings and attitudes toward nature and place. This was inspired by a collaborative project between architect Peter Zumthor and a literature group in Detmold, Germany (Ventura, 2007).

The students make use of a previously researched palette of architectonic landscape devices, such as the use of framed views, threshold devices, the ha-ha, use of axis, focus, hiding and revealing, and making an event of level change (Steenbergen 2008). The more fluid drawings of the workshops contribute to the "feel" of the installations and their sensuous and textural qualities.

We have also introduced a second drawing workshop later in the design stage. This is a valuable reminder to the students of how they can express their ideas lyrically through media other than the computer. It encourages them to be imaginative with the presentation of their schemes, particularly with composite drawings.

We ask students to reflect on their films to think of how they will create a particular atmosphere within their designs, and what choice of materials they will employ and manipulate to convey it. We have found that the film is a good vehicle for enabling the students to think through the experience that visitors will have as they travel through the site.

We promote moving from the general to the particular and back again in the design process. For example, making use of film techniques such as close-up and panoramic view associated with landscape ideas can have a direct relevance to drawing at different scales to work through a design problem. 
Although we do not expect any detailed knowledge of plants, students must understand what species with thrive in the locality and provide outline soft landscaping details to go with more detailed hard landscaping (Figure 8).

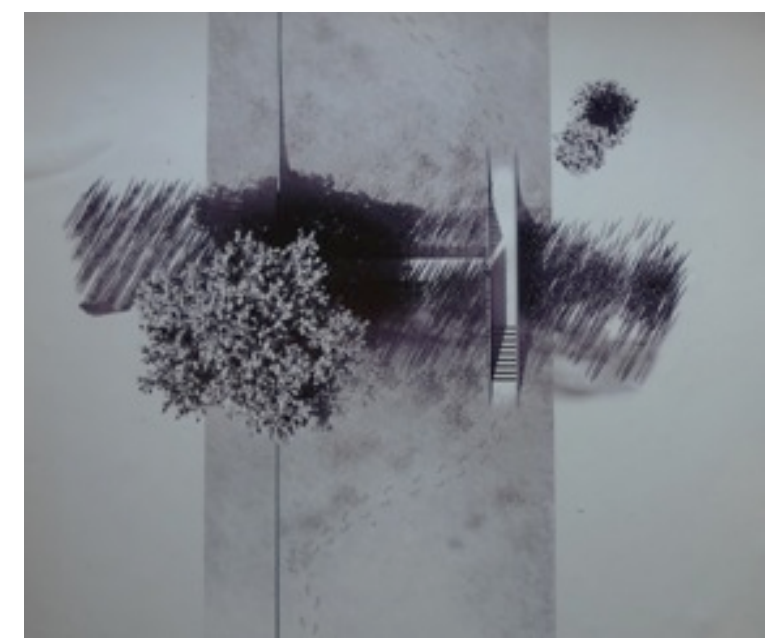

Figure 8: Tempietto, Agrigento, Sicily, (Graham Lake)

\section{Conclusion}

One of the problems students of architecture always face is that their final designs can never be the art object itself. "Fly-throughs" can only be seen through a screen, and cannot give one the experience of the reality. Models help, but are always scaled down interpretations of the real thing. Drawings by their nature are two-dimensional.

Each of the exercises we have described demands a different method of representation that, cumulatively, becomes a valuable and transferable skill base. However, the real value is in the cross referencing they allow.

All student research is gathered and compiled into a book, carefully edited and fully bound. The information is put together roughly at an early stage and used as a resource throughout the project. A model of the whole landscape, although it will inevitably be at a very small scale (and will vary in scale depending on the location), is surprisingly helpful to understand the topography. This is a useful means of describing the overall strategy. Larger models, usually at the scale of 1:100, are made of the installations themselves that explore their materiality and context, their connectivity with the land. These all accompany the more conventional plans and sections and 3-D drawings. We encourage presentations that are of both digital and hand-drawn images. The film also becomes part of their presentation, setting the scene. The range of media helps to bring out different aspects of the design, and also allows for the different strengths of the students to be exploited. It is never easy to achieve a balance between the gathering of hard facts and ensuring that students have the freedom to explore ideas imaginatively and conceptually during the design process.

As our world becomes more urbanized, the need to nurture the countryside that supports us is paramount. It is becoming increasingly important to expose students to landscape issues and for them to develop an informed attitude to the landscape around us as a whole.

We have found that using this range of projects and methodologies for a series of short projects where the emphasis varies in each, it has helped their engagement with all the complexities involved in designing architecture that has a "sense of place," and to develop a responsible and informed attitude toward our environment. 


\section{References}

Bruno, G. (2007). Atlas of emotion: Journeys in art, architecture and film. New York: Verso.

Buchanan, P. (2012). The big rethink: Place and aliveness: Pattern, play and the planet. Architectural Review, 231(1386). Retrieved from http://www.architecturalreview.com/confirmation?rtn=/ the-big-rethink-place-and-aliveness-pattern-play-and-theplanet/8633314.article

Harper, G., \& Rayner, J. (2010). Cinema and landscape: Film, nation and cultural geography. Chicago, ILL: University of Chicago Press.

Holl, S., Pallasmaa, J., \& Pérez-Gómez, A. (1994). Questions of perception phenomenology of architecture. Tokyo: $\mathrm{A}+\mathrm{U}$.

Jones, W. (Ed.) (2011). Architects'sketchbooks. London: Thames \& Hudson.

Lamster, M. (Ed.) (2000). Architecture and film. New York: Princeton Architectural Press.

Nesbitt, K. (Ed.) (1996). Theorizing a new agenda for architecture. An anthology of architectural theory 1965-1995. New York: Princeton Architectural Press.

Pallasmaa, J. (2009). The thinking hand. New York: John Wiley \& Son.

Pizzoni, P. (1999). The garden: A history of landscape and art. (Trans. J. Landry). London: Arum.

Shepherd, J. C., \& Jellicoe, G. A. (1993). Italian gardens of the Renaissance. New York: Princeton Architectural Press,

Steenbergen, C. (2008). Composing landscapes: Analysis, typology and experiments for design. Berlin: Birkhauser.

Steenbergen, C., \& Reh, W. (2003) Architecture and landscape. The design experiment of the great European gardens and landscapes. Berlin: Birkhauser.

Symes, M., (2012). The picturesque and the later Georgian garden. Bristol, UK: Redcliffe.

Tilley, C. (1994). A phenomenology of landscape: Places, paths and monuments. Oxford: Berg.

Ventura, S. (2007). Poetic landscape. Retrieved from http://www.academia.edu/2990492/Poetic_Landscape

Copyright @ 2014 Kate Baker 